\title{
A comparison of the diet and lifestyle of Greek-Cypriot university students living in Cyprus and the UK
}

\author{
E. Paraskeva and J. Bradbury \\ School of Applied Sciences, Queensgate, University of Huddersfield, HD1 3DH
}

Numerous studies report adverse nutritional outcomes during long-term migration such as chronic diseases and obesity ${ }^{(1-3)}$. However, only a few studies have investigated the health impacts of short-term migration, as is the case for International students. Leaving home and starting university represents a period of increasing responsibility, regarding food purchasing, planning and preparing meals ${ }^{(4)}$, whereas simultaneously, young adults often lack the qualifications for of these experiences ${ }^{(5)}$. The aim of this study was to determine whether the short-term translocation to a northern European environment of a group of Greek-Cypriot students changed their dietary habits compared with Greek-Cypriot students living away from the family home but remaining in Cyprus.

A cross-sectional study was conducted to assess the eating habits of Greek-Cypriot university students living away from home in the UK or in Cyprus. Data about eating habits were collected online using a food frequency questionnaire, and additional questions asked about responsibility for shopping and food preparation and what changes, if any, had been made. Participants were recruited via Universities' Greek-Cypriot Societies in the UK and Cyprus.

Two hundred and ten Greek-Cypriot students, half studying in the UK ( $\mathrm{n}=110,65 \%$ female) and half in Cyprus ( $\mathrm{n}=100,68 \%$ female, $p=0.597$ ) completed the eating habits questionnaire. Ages ranged from 18-32 years, with the Cypriot students living in the $\mathrm{UK}$ significantly older $[\mathrm{Mdn}=21 \mathrm{yrs}(\mathrm{IQR}=3 \mathrm{yrs}) v s .20 \mathrm{yrs}(2 \mathrm{yrs}), p=0 \cdot 040]$. BMI was not different $\left[23 \mathrm{~kg} / \mathrm{m}^{2}\left(5 \cdot 1 \mathrm{~kg} / \mathrm{m}^{2} v s .22 \cdot 5\right.\right.$ $\left.\mathrm{kg} / \mathrm{m}^{2}\left(5.3 \mathrm{~kg} / \mathrm{m}^{2}\right), p=0.938\right]$. Students in the UK compared with students in Cyprus reported a significantly lower consumption of fruits (4 portions/d vs. 5 portions/d, $p=0.024)$ and snacks $(1.4$ snacks/d $v s .1 .9$ snacks $/ \mathrm{d}, p=0.026)$. Both groups consumed two portions of fish per week. The majority used olive oil for cooking. A higher consumption of low-fat and wholegrain products was reported by students in the UK. Students living in the UK reported consuming homemade food more often and take away food less often than students in Cyprus. Limited availability, higher prices, and poor quality of familiar food were reported by students living in UK as the major barriers to maintaining their usually dietary habits.

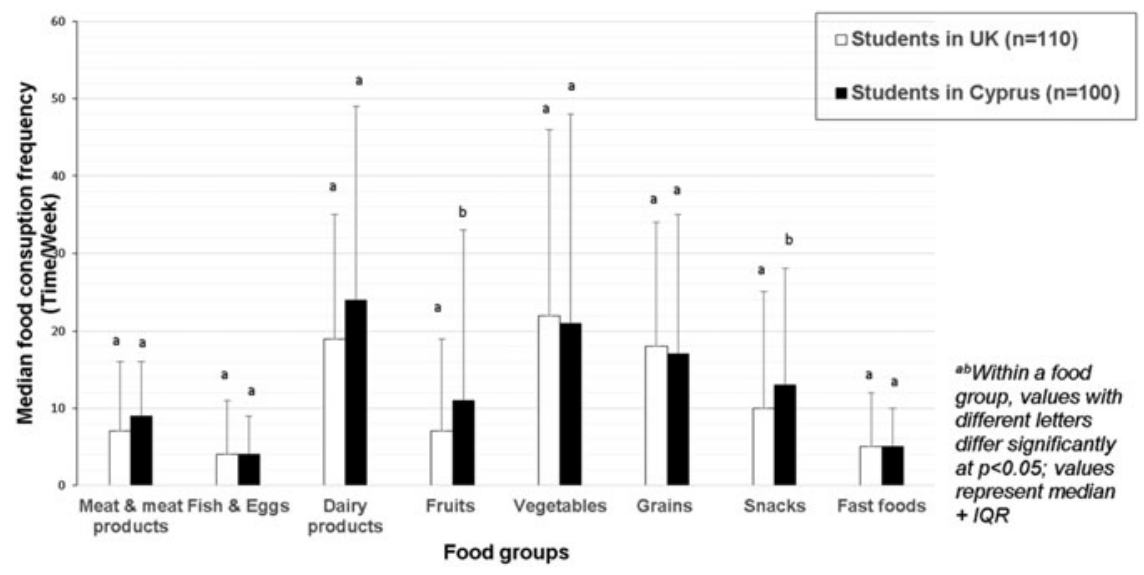

Despite the difficulties experienced by Greek-Cypriot students studying in the UK, there were few differences in their eating habits compared with Greek-Cypriot students studying in Cyprus, suggesting that there are factors common to students associated with leaving home and becoming responsible for food shopping and preparation.

1. Will B, Zeeb H \& Baune BT (2005) BMC Public Health 5, 45-45.

2. Kumar BN, Meyer HE, Wandel M et al. (2006) Int J Obes 30, 684-690.

3. Nicolaou M, Stronks K \& Dam VRM (2006) JHND 19, 383-393.

4. Coli Bari I, Satali Z \& Lukeši E (2003) IJNFS 54, 473-484.

5. Larson NI, Perry CL, Story M et al. (2006) JAND 106, 2001-2007. 